\section{Reply to the Comment on:}

"Generation and Detection of Gaseous $\mathrm{W}_{12} \mathrm{O}_{41}^{-\bullet}$ and Other Tungstate Anions by Laser Desorption Ionization Mass Spectrometry" by Julius Pavlov, Washington Braida, Adebayo Ogundipe, Gregory $\mathrm{O}^{\prime}$ Connor, and Athula B. Attygalle, J. Am. Soc. Mass Spectrom. 2009, 20, 1782-1789.

$\mathrm{F}$ or several decades, the aqueous chemistry of tungsten oxo-salts has been the subject of numerous studies by a variety of analytical techniques under varied experimental conditions. Frequently, different conclusions have been made leading to frequent revisions of previously widely accepted "facts." For example, paratungstate $\mathrm{A}$, the accepted predominant species present in unaged samples kept at $\mathrm{pH} 5-7$, which was originally validated to be $\mathrm{HW}_{6} \mathrm{O}_{21}^{5-}[1,2]$, was subsequently changed to $\mathrm{W}_{7} \mathrm{O}_{24}^{6-}$ [3]. However, $\mathrm{HW}_{6} \mathrm{O}_{21}^{5-}$ continued to be accepted for many years before $\mathrm{W}_{7} \mathrm{O}_{24}^{6-}$ was conclusively recognized as the formula for paratungstate A [1]. Thus, we have no objections to the suggested chemical formulas. However, we wish to point out that sodium metatungstate, which we purchased from Aldrich Chemical Company, is shown in their recent catalog as $3 \mathrm{Na}_{2} \mathrm{WO}_{4} \cdot 9 \mathrm{WO}_{3}$ (CAS 12,14167-2), which is the formula we used in our paper.

We were aware of the very low solubility of the tungsten oxides and calcium and lead tungstates in any solvent. For our LDI-MS investigations, we used only the supernatants of aqueous and organic suspensions prepared by shaking the solids for $2 \mathrm{~h}$ in a solvent (100 $\mathrm{mg}$ tungsten/L). Our results demonstrated that the limit of detection of tungsten by this technique is exceedingly low because the solubilities of the compounds used were very low, and only a microliter of the supernatant was used to make deposits for irradiation experiments.

As Lunk states, the literature on tungsten chemistry before our paper [4] does not report the observation of $\mathrm{W}_{12}$ species from poorly soluble compounds such as $\mathrm{CaWO}_{4}$ and $\mathrm{PbWO}_{4}$. However, these compounds have previously not been examined by such a sensitive technique as LDI-MS. In fact, there have been only a few MS studies on tungsten compounds [5-9]. The relative intensity of $\left[\mathrm{W}_{12} \mathrm{O}_{41}\right]^{-\bullet}$ peak is about $10 \%-12 \%$ in our spectra recorded from deposits made from aqueous $\mathrm{CaWO}_{4}$ and $\mathrm{PbWO}_{4}$, and $35 \%$ in the spectra of $\mathrm{WO}_{2}$. Clearly, mass spectrometry is the only technique capable of detecting such low levels of these ions in complex matrices.

Address reprint requests to Professor A. Attygalle, Department of Chemistry, Chemical Biology, and Biomedical Engineering, Center for Mass Spectrometry, Stevens Institute of Technology, Castle Point on Hudson, Hoboken, NJ 03030, USA. E-mail: aattygal@stevens.edu
The presence of peaks for $\left[\mathrm{W}_{12} \mathrm{O}_{41}\right]^{-\bullet}$ in the spectra obtained from aqueous deposits of compounds of low solubility was unprecedented. As pointed out by Lunk, its presence could have been easily attributed to its formation in the ion source. It was precisely this working hypothesis that motivated us to analyze samples of pristine compounds and deposits from organic solvents. However, the in-source formation of $\left[\mathrm{W}_{12} \mathrm{O}_{41}\right]^{-}$ is less likely for two reasons. First, the only variable in our experiments was the solvent used for the sample preparation. The mass spectrometric conditions were the same for the different compounds. Lunk suggests that "the interaction of $\mathrm{CaWO}_{4}$ and $\mathrm{PbWO}_{4}$ with water is the precondition for forming the cluster of $\left[\mathrm{W}_{12} \mathrm{O}_{41}\right]^{-\bullet}$ in the ion source." However, water is unlikely to assist the in-source formation of any ion, because the deposits had been thoroughly dried before analysis. The minuscule dissolved amount of a poorly soluble salt would crystallize to the original salt and yield the same mass spectrum as the pristine salt, unless there was a reaction with the solvent in solution that would generate additional species and change the mass spectrum. Thus, it is reasonable to conclude that the interaction of the dissolved oligomeric tungstates with water before drying afforded the formation of $\left[\mathrm{W}_{12} \mathrm{O}_{41}\right]^{-\bullet}$ This conclusion is corroborated by the fact that the intermediate-mass tungsten-bearing peak clusters are far more numerous (up to $\mathrm{W}_{6}$ ) in the spectra of $\mathrm{PbWO}_{4}$ and $\mathrm{CaWO}_{4}$ deposited from aqueous solutions than in the spectra of pristine salts, or salts deposited from organic solvents. In other words, when the starting tungstate salts have been in contact with water, polymerization is observed. Lunk does not comment on the observation of peaks for intermediate-mass tungstate polymeric species. On the contrary, it is stated that "the dried spots ... contain sufficiently reactive oligomeric "clusters" of the starting monotungstates, which are being converted into the radical ion $\mathrm{W}_{12} \mathrm{O}_{41}^{-}$in the ion source." However, it is not clear what is meant by "oligomeric clusters." The only ions that may be termed monomers or oligomers are $\mathrm{WO}_{3}^{-}$and $\mathrm{HWO}_{4}^{-}$, for which we have observed peaks in all the spectra we recorded. Moreover, the suggested in-source formation of $\left[\mathrm{W}_{12} \mathrm{O}_{41}\right]^{-\bullet}$ is unable to rationalize why the same alleged starting building blocks should combine differently after laser ablation to produce $\left[\mathrm{W}_{12} \mathrm{O}_{41}\right]^{-\bullet}$ only in some cases but not in others. Furthermore, Lunk does not provide an explanation on why peaks for $W_{7}$ to $W_{11}$ species are not observed in the spectra of $\mathrm{CaWO}_{4}$ and $\mathrm{PbWO}_{4}$.

Second, if in-source formation of $\left[\mathrm{W}_{12} \mathrm{O}_{41}\right]^{-\bullet}$ were a possibility, one would expect the peak for $\left[\mathrm{W}_{12} \mathrm{O}_{41}\right]^{-}{ }$in the spectra of sodium tungstate and metatungstate, which are much more soluble, to be more intense than those for the of oligomeric tungstate fragments. How- 
ever, in both cases peaks for tungsten species larger than $\mathrm{W}_{4}$ and $\left[\mathrm{W}_{12} \mathrm{O}_{41}\right]^{-\bullet}$ are conspicuously absent.

The exact chemical structure corresponding to the low-abundance peak cluster assigned as $\left[\mathrm{Pb}\left(\mathrm{W}_{12} \mathrm{O}_{42}\right)\right]^{-}$• has not been established. We do agree that the observed species may not be a "true" Keggin ion, and the position of $\mathrm{Pb}$ has yet to be determined. The statement that the tetrahedral cavity in a $\left[\mathrm{H}_{2} \mathrm{~W}_{12} \mathrm{O}_{40}\right]^{6-}$ (metatungstate) is spacious enough to accommodate one of at least 35 different cations to yield heteropolytungstates was a citation from Wulfsberg's Inorganic Chemistry [10]. However, it does not mean that there are 35 known Keggin ions.

Lastly, we wish to emphasize that the purpose of our work was to evaluate the applicability of LDI-MS to the chemistry of tungstates, not only for environmental research, but as a general procedure for basic science. Thus, we investigated all tungsten compounds available. We disagree with the indication that $\mathrm{WO}_{2}$ is unlikely to be present outside of manufacturing facilities, and so should be ruled out a priori as a research target. In LDI-MS, it is possible to compile libraries of spectra similar to compilations of X-ray diffractogram databases. Even though $\mathrm{XRD}$ is capable of distinguishing one chemical compound from another, say $\mathrm{WO}_{2}$ from $\mathrm{WO}_{3}$, LDI-MS has many advantages because it produces results fast, requires only nano- to picogram quantities of material, needs minimal sample preparation, and deals with mixtures, complex matrices, and even with noncrystalline materials. However, the intention of our paper was not to provide a comparative account on analytical techniques available for tungsten compounds.
Athula Attygalle

Department of Chemistry, Chemical Biology, and Biomedical Engineering, Center for Mass Spectrometry, Stevens Institute of Technology, Hoboken, New Jersey, USA

\section{References}

1. Ogundipe, A.; Pavlov, J.; Braida, W.; Koutsospyros, A.; Sen, G.; Christodoulatos, C.; O'Conner, G. Evaluation of Analytical Methods to Address Tungsten Speciation. Global NEST 2009, 11(3), 308-317.

2. Jander, G.; Mojert, D.; Aden, T. Über amphotere Oxydhydrate, deren wäßrige Lösungenund kristallisierende Verbindungen. VIII. Mitteilung. Über Wolframate, Isopoly- und Heteropoly-Wolframsäuren, Z. Anorg. Allg. Chem. 1929, 180(1), 129-149.

3. Sasaki Y. Equilibrium Studies of Polyanions. Acta Chem. Scand. 1961, 15, 175-189.

4. Pavlov, I.; Braida, W.; Ogundipe, A.; O'Connor, G.; Attygalle, A. Generation and Detection of Gaseous $\mathrm{W}_{12} \mathrm{O}_{41}^{-\bullet}$ and Other Tungstate Anions by Laser Desorption Ionization Mass Spectrometry. J. Am. Soc. Mass Spectrom. 2009, 20, 1782-1789.

5. Deery, M. J.; Howarth, O. W.; Jennings, K. R. Application of Electrospray Ionization Mass Spectrometry to the Study of Dilute Aqueous Oligomeric Anions and Their Reactions. J. Chem. Soc. Dalton Trans. 1997, 4783-4788.

6. Walanda, D. K.; Burns, R. C.; Lawrance, G. A.; von Nagy-Felsobuki, E. I. Electrospray Mass Spectrometry of Aqueous Solutions of Isopolyoxotungstates. J. Cluster Sci. 2000, 11, 5-28.

7. Le Quan Tuoi, J.; Müller, E. Electrospray Mass Spectrometry on a Magnetic-Sector Instrument Applied to Heteropolyoxoacids. Rapid Commun. Mass Spectrom. 1994, 8, 692-694.

8. Lau, T. C.; Wang, J.; Guevremont, R.; Siu, W. M. Electrospray Tandem Mass Spectrometry of Polyoxoanions. J. Chem. Soc. Chem. Commun. 1995, 8, 877-878.

9. Ma, M. T.; Waters, T.; Beyer, K.; Palamarczuk, R.; Richardt, P. J. S.; O'Hair, R. A. J.; Wedd, A. G. Gas-Phase Fragmentation of Polyoxotungstate Anions. Inorg. Chem. 2009, 48, 598-606.

10. Wulfsberg, G. Inorganic Chemistry; University Science Books: Sausalito, CA, 2000, pp 715-716. 